\title{
Removal of Basic Blue 41 dyes using Persea americana-activated carbon prepared by phosphoric acid action
}

\author{
Abdelmajid Regti ${ }^{1}$ - My Rachid Laamari ${ }^{1}$ - Salah-Eddine Stiriba ${ }^{2,3}$. \\ Mohammadine El Haddad ${ }^{1}$
}

Received: 16 February 2016/ Accepted: 29 June 2016/Published online: 18 July 2016

(c) The Author(s) 2016. This article is published with open access at Springerlink.com

\begin{abstract}
Adsorption study of Basic Blue 41 dye onto activated carbon from Persea americana nuts with phosphoric acid activation was achieved. The effect of operating parameters, the effect of $\mathrm{pH}(2-12)$, adsorbent amount (5-30 mg/50 mL), dye concentration (25-125 mg/L), contact time (0-200 min) and temperature (298-323 K), on the adsorption capacity was examined. The experimental isotherm data were analyzed using Langmuir and Freundlich models, which showed that the best fit was achieved by the Langmuir model with the maximum monolayer adsorption capacity at $625 \mathrm{mg} / \mathrm{g}$. The adsorption kinetic process followed pseudo-second-order kinetics. Thermodynamic evaluation showed that the process was endothermic $\left(\Delta H^{0}=144.60 \mathrm{~kJ} / \mathrm{mol}\right)$ and spontaneous ( $\Delta G^{0}$ varied from to -11.64 to $-19.50 \mathrm{~kJ} / \mathrm{mol}$ ), while the positive value of entropy $\left(\Delta S^{0}=524.3 \mathrm{~J} / \mathrm{mol} \mathrm{K}\right)$ revealed increased randomness at the adsorbent-adsorbate interface. It was found to be a very efficient adsorbent and a promising alternative for dye removal from aqueous solutions.
\end{abstract}

Mohammadine El Haddad

elhaddad71@gmail.com

1 Equipe de Chimie Analytique and Environnement, Faculté Poly-disciplinaire, Université Cadi Ayyad, BP 4162, 46000 Safi, Morocco

2 Equipe de Chimie Moléculaire, Matériaux et Modélisation, Faculté Poly-disciplinaire, Université Cadi Ayyad, BP 4162, 46000 Safi, Morocco

3 Instituto de Ciencia Molecular/ICMol, Universidad de Valencia, C/. Catedrático José Beltrán 2, Paterna, 46980 Valencia, Spain
Keywords Removal of dye - Persea americana-activated carbon - Surface area - Adsorption - Kinetics and thermodynamic studies

\section{Introduction}

The textile industry plays a part in the economy of several countries around the world. However, effluents from textile and dyeing have a low biological oxygen demand and strong chemical oxygen demand. Disposal of this colored water into receiving water can be toxic to aquatic life and cause food chain contamination, resulting in deleterious health effect even in very low concentrations. Moreover, most of these dyes can cause allergy, dermatitis, skin irritation and also provoke cancer and mutation in humans $[1,2]$. Dyes are usually highly visible, very difficult to biodegrade, and extremely difficult to eliminate in natural aquatic environments [3, 4].

To improve the effluent quality, the addition of physical and/or chemical treatments comprising adsorption [5-9], photocatalytic [10,11] or electrochemical methods [5] and reverse osmosis [12] are necessary. Adsorption is the most simple and known for the treatment of effluents containing dyes using the new low-cost and environmentally friendly adsorbents in the carbon-based or not activated means [13-18].

The potential properties of activated carbon as adsorbents are due to their highly developed porosity, favorable pore size distribution, large surface area, and high degree of surface reactivity [19]. Chemical activation and physical activation are two methods for the preparation of activated carbon. Chemical activation uses chemical agents for the preparation of activated carbon in a single step method, while physical activation involves carbonization of 
carbonaceous materials followed by activation of the resulting substrate in the presence of dioxide carbon or steam as activating agents [20]. It is recognized that the carbon yields of chemical activation are higher than the physical one. The most common precursors used for the production of activated carbon are organic materials that are rich in carbon.

Several studies to find low-cost carbonaceous materials have been reported. These materials include Jerusalem artichoke [21], waste rice hulls [22], homemade cocoa shell [23], waste tea [24], coir pith [25], orange peels [26], jute sticks [27], walnut [28], palm oil shell [29], Acacia mangium wood [30] and waste tires [31].

In the present study, we examine the feasibility of using activated carbon prepared using Persea americana as adsorbent for the removal of Basic Blue 41 dyes from aqueous solutions. The effect of different parameters including solution $\mathrm{pH}$, adsorbent dosage, dye concentration, temperature and contact time were studied to optimize the adsorption process. The isotherm and kinetic and thermodynamic parameters were examined to analyze the experimental data.

\section{Materials and methods}

The Persea americana nuts were collected, washed with distilled water and dried at ambient temperature for several days. The unmodified Persea americana nuts were abbreviated as PAN. The carbonization of PAN was carried out using an appropriate weight of PAN and $25 \mathrm{~mL}$ concentrated phosphoric acid with a mass ratio (1:4). A glass beaker of $100 \mathrm{~mL}$ was heated to $500{ }^{\circ} \mathrm{C}$ for $1 \mathrm{~h}$ producing a black carbonaceous residue. The solid material was neutralized with $\mathrm{KOH}$ solution until a neutral $\mathrm{pH}$ was obtained. The resulting carbonized Persea americana nut (C-PAN) was filtered and washed intensively with water. The C-PAN was then dried at $100{ }^{\circ} \mathrm{C}$ for $2 \mathrm{~h}$ and kept in desiccators for further use.

The characterization of C-PAN was achieved by FT-IR spectroscopy and X-ray powder diffraction measurements. FT-IR spectra (4000-450 $\mathrm{cm}^{-1}$ range) were recorded with a Nicolet 5700 FT-IR spectrometer on samples prepared as $\mathrm{KBr}$ pellets. The polycrystalline sample of each adsorbent was lightly ground in an agate mortar and pestle and filled into $0.5 \mathrm{~mm}$ borosilicate capillary prior to being mounted and aligned on an Empyrean PANalytical powder diffractometer using $\mathrm{Cu} \mathrm{K}_{\alpha}$ radiation $(\lambda=1.54056 \AA)$. Three repeated measurements were obtained at room temperature in the $10^{\circ}<2 \theta<60^{\circ}$ range with a step size of $0.01^{\circ}$. Scanning electronic microscopy (SEM) images were obtained with HITACHI-S4100 equipment operated at $20 \mathrm{kV}$.
Adsorption-desorption isotherms of nitrogen at $-196{ }^{\circ} \mathrm{C}$ were measure with an automatic adsorption instrument (NOVA-1000 Gas Sorption analyzer) to determine the surface areas and total pore volumes. The BET surface area and the total pore volumes of the obtained Persea americana-activated carbon were found to be 1593 and $1.053 \mathrm{~cm}^{3} / \mathrm{g}$, respectively.

Deionized water was used throughout the experiments for solution preparation. The adsorption studies for evaluation of the C-PAN adsorbent for the removal of the Blue Basic 41 dye from aqueous solutions were carried out in triplicate using the batch contact adsorption method. Basic Blue 41 dye used in this study, abbreviated as BB41, was purchased from Sigma-Aldrich. The chemical structure of BB41 is shown in Fig. 1.

For the adsorption experiments, fixed amounts of adsorbents $(5-30 \mathrm{mg}$ ) were placed in a $100 \mathrm{~mL}$ glass Erlenmeyer flask containing $50 \mathrm{~mL}$ of dye solution at various concentrations $(25-125 \mathrm{mg} / \mathrm{L})$, which were stirred for a suitable time (5-200 $\mathrm{min}$ ) from 293 to $313 \mathrm{~K}$. The $\mathrm{pH}$ of the dye solutions ranging from 2 to 10 was adjusted by $0.1 \mathrm{M} \mathrm{HCl}$ or $0.1 \mathrm{M} \mathrm{NaOH}$ to investigate the effect of $\mathrm{pH}$ on the adsorption processes. Subsequently, to separate the adsorbents from the aqueous solutions, the samples were centrifuged at $3600 \mathrm{rpm}$ for $10 \mathrm{~min}$, and aliquots of $1-10 \mathrm{~mL}$ of the supernatant were taken. At a predetermined time, the residual dye concentration in the reaction mixture was analyzed by centrifuging the reaction mixture and then measuring the absorbance by UV-visible spectroscopy of the supernatant at the maximum absorbance wavelength of the sample at $606 \mathrm{~nm}$.

The amount of equilibrium adsorption $q_{\mathrm{e}}(\mathrm{mg} / \mathrm{g})$ was calculated using the formula:

$q_{\mathrm{e}}=\frac{C_{0}-C_{\mathrm{e}}}{W} V$,

where $C_{\mathrm{e}}(\mathrm{mg} / \mathrm{L})$ is the liquid concentration of the dye at equilibrium, $C_{0}(\mathrm{mg} / \mathrm{L})$ the initial concentration of the dye in solution, $V$ the volume of the solution $(L)$ and $W$ the mass of the dye biosorbent $(\mathrm{g})$. The BB41 removal percentage $(\%)$ can be calculated as follows:

$\%$ Removal $=\frac{C_{0}-C_{\mathrm{e}}}{C_{0}} \times 100$,

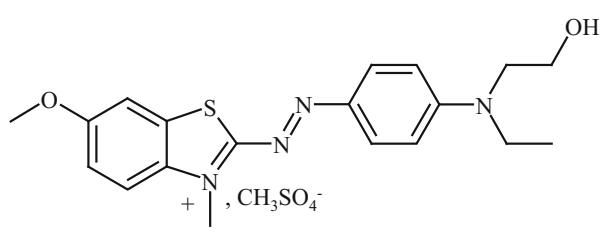

Fig. 1 The chemical structure of Basic Blue 41 
where $C_{0}(\mathrm{mg} / \mathrm{L})$ is the initial dye concentration and $C_{\mathrm{e}}$ $(\mathrm{mg} / \mathrm{L})$ is the concentration of the dye at equilibrium.

\section{Results and discussion}

\section{Characterization of C-PAN adsorbent}

To investigate the surface characteristics of the C-PAN adsorbent, FT-IR and XRD spectra were recorded. As shown in the FT-IR spectrum in Fig. 2, the frequencies of the absorption bands of C-PAN are 876, 1074, 1149, 1563, 2916 and $3415 \mathrm{~cm}^{-1}$. The absorption band at $3415 \mathrm{~cm}^{-1}$ is attributed to the hydroxyl group $(\mathrm{O}-\mathrm{H})$ vibration [32]. The bands at 2916, 1563 and $1381 \mathrm{~cm}^{-1}$ correspond, respectively, to unsymmetrical aliphatic $\mathrm{C}-\mathrm{H}$ stretching, $\mathrm{C}=\mathrm{C}$ stretching of aromatic rings and aromatic $\mathrm{C}=\mathrm{C}$ stretching vibration. The band at $1149 \mathrm{~cm}^{-1}$ is ascribed to $\mathrm{C}-\mathrm{O}$ stretching in alcohol or ether or the hydroxyl group $[33,34]$. The bands at 1074 and $876 \mathrm{~cm}^{-1}$ could result from ionized linkage of $\mathrm{P}+\mathrm{O}-$ in acid phosphate esters, to symmetrical vibration in a chain of $\mathrm{P}-\mathrm{O}-\mathrm{P}$ and to $\mathrm{P}-\mathrm{C}$ phosphorus-containing compound $[35,36]$. These functional groups are due to the presence of $\mathrm{H}_{3} \mathrm{PO}_{4}$ acid as an activation agent in the preparation of C-PAN.

Figure 3 shows an X-ray powder diffraction pattern of C-PAN. An amorphous peak with the equivalent Bragg angle at $2 \theta=24.6$ was recorded, together with other peaks recorded at $2 \theta=17.5^{\circ}, 31.2^{\circ}$ and $47.5^{\circ}$. The surface morphology of the C-PAN adsorbent was examined. Figure 4 shows the SEM image indicating that the surface is relatively smooth and contains many pores. The SEM of C-PAN show very distinguished dark spots, which can be taken as a sign for effective adsorption of dye molecules in the cavities and pores of this adsorbent.

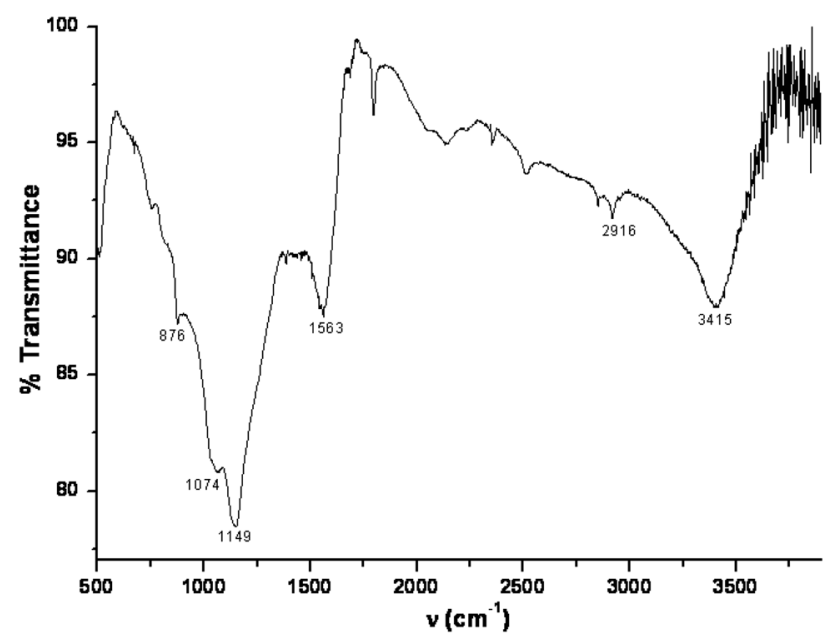

Fig. 2 FT-IR spectrum of C-PAN adsorbent

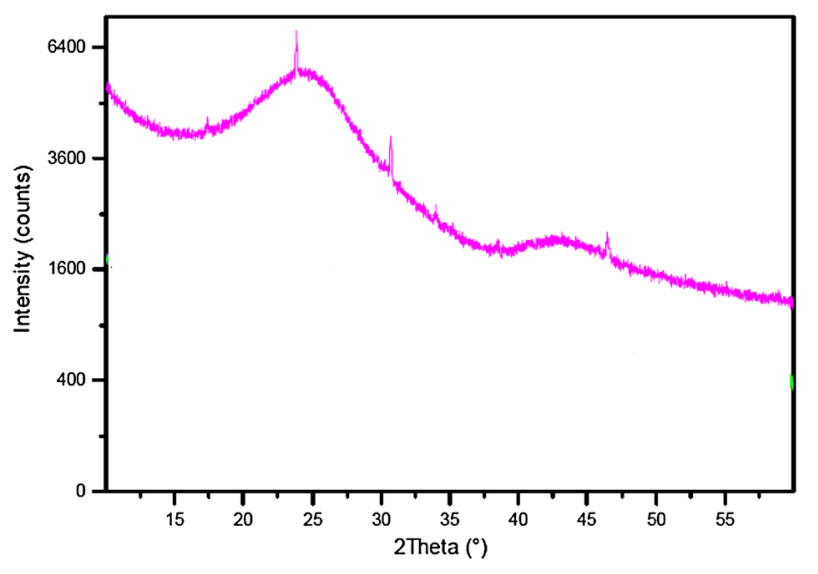

Fig. 3 XRD spectrum of C-PAN adsorbent

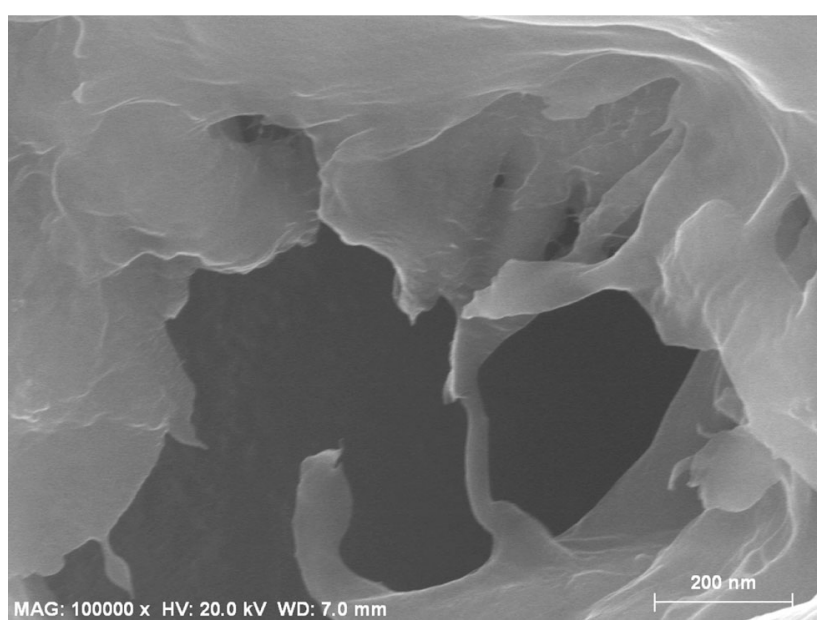

Fig. 4 SEM image of C-PAN adsorbent

\section{Effect of pH}

To examine the $\mathrm{pH}$ effect of the initial aqueous dye solution, a concentration of BB41 dye at $100 \mathrm{mg} / \mathrm{L}$ and $20 \mathrm{mg}$ of C-PAN adsorbent was used, keeping the temperature at $20{ }^{\circ} \mathrm{C}$ at different $\mathrm{pH}$ values in the range $2-12$. Figure 5 shows the variation of dye removal vs. $\mathrm{pH}$. In fact, the amount of dye adsorbed onto C-PAN was found to be constant for all $\mathrm{pH}$ values being studied. The experiments carried out at different $\mathrm{pH}$ values showed that there was no significant change in the percent removal of dye over the entire $\mathrm{pH}$ range. This indicates the strong affinity of the dye to C-PAN and that either $\mathrm{H}^{+}$or $\mathrm{OH}^{-}$ions could influence the dye adsorption capacity. The dye removal $\%$ uptake comprised between 92 and $97 \%$. If the adsorption would have occurred through an ion exchange mechanism, there should have been an influence on the dye adsorption while varying the $\mathrm{pH}$. This observation and the high positive $\Delta H^{0}$ value obtained indicate irreversible adsorption, probably 


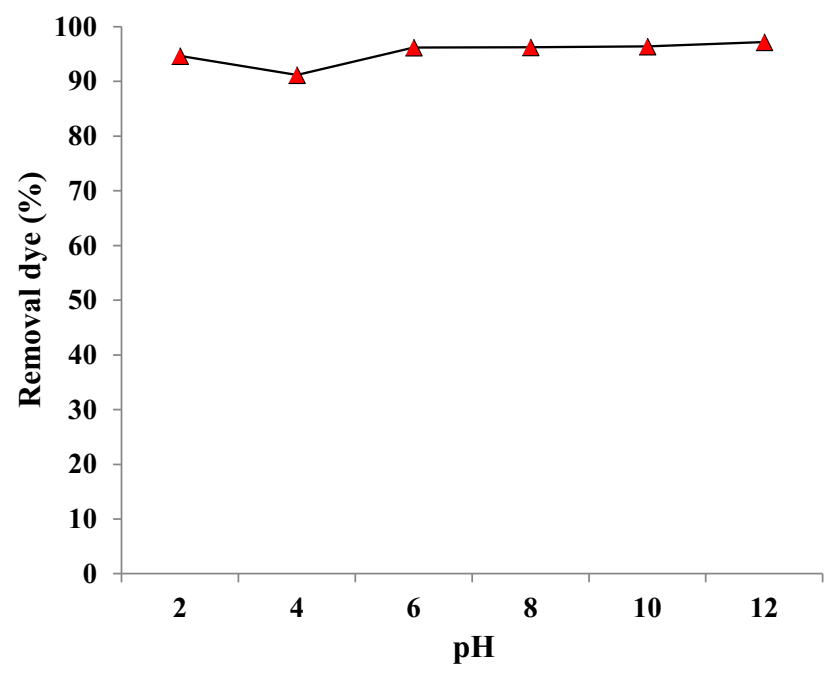

Fig. 5 Effect of $\mathrm{pH}$ on the removal of BB41 from aqueous solution onto C-PAN. Initial dye concentration $100 \mathrm{mg} / \mathrm{L}$; adsorbent amount $200 \mathrm{mg}$; agitation time $80 \mathrm{~min}$; temperature $20^{\circ} \mathrm{C}$

due to nonpolar interactions [37]. Other studies for different dyes were also found to be independent of $\mathrm{pH}$ [37-39].

\section{The effect of C-PAN adsorbent dosage}

The effect of C-PAN dosage on adsorption was studied at $20{ }^{\circ} \mathrm{C}$ with $100 \mathrm{mg} / \mathrm{L}$ dye solution. The adsorbent dosage ranged from 5 to $30 \mathrm{mg}$. The plots of dye removal (\%) versus time at different adsorbent dosages are shown in Fig. 6. The results follow the expected pattern, in which the removal (\%) of BB41 increased with increase in C-PAN adsorbent dosage. This might be due to an increase in the surface active sites in C-PAN samples. The adsorption

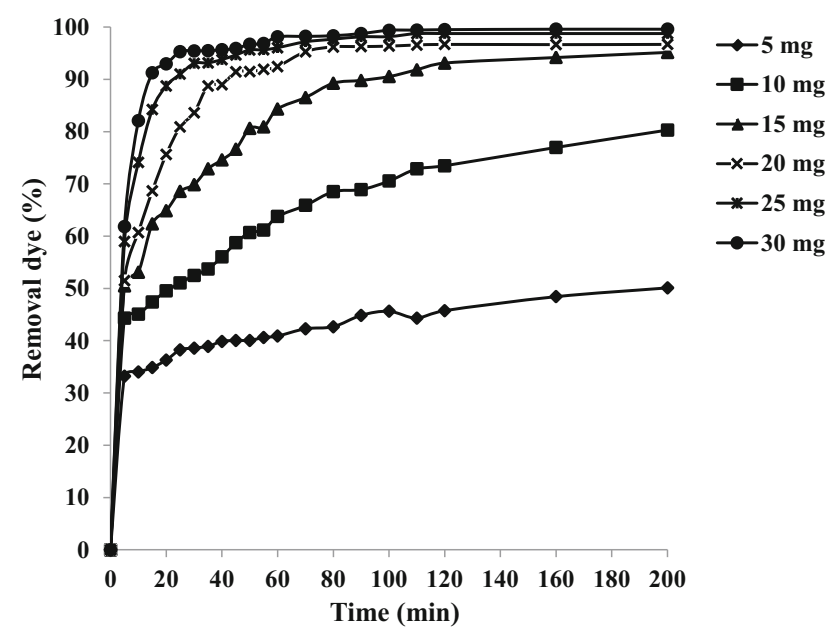

Fig. 6 Effect of C-PAN adsorbent dosage and contact time on the removal of BB41 from aqueous solution. Initial dye concentration $100 \mathrm{mg} / \mathrm{L}$; temperature $20^{\circ} \mathrm{C}$ equilibrium was achieved after $120 \mathrm{~min}$ of stirring the dye solution with the appropriate amount of C-PAN adsorbent. At this time, the removal of BB41 (\%) increased from 45.7 to $99 \%$ for C-PAN adsorbent dosage of $5 \mathrm{mg}$ to $30 \mathrm{mg}$. However, the amount of BB41 adsorbed onto C-PAN, $q(\mathrm{mg} / \mathrm{g})$ was found to decrease from 457.46 to $165.83 \mathrm{mg} /$ $\mathrm{g}$ upon increasing the adsorbent dosage. This behavior could be due to the high number of unsaturated sorption sites during the adsorption process.

\section{Effect of BB41 concentration}

The initial adsorbate concentration provides an important driving force to overcome all mass transfer resistances of dye between the aqueous and solid phases. The effect of initial concentration of dye on the adsorption was studied at $20^{\circ} \mathrm{C}$ with $30 \mathrm{mg}$ of C-PAN adsorbent. The adsorbate concentration ranged from 25 to $125 \mathrm{mg} / \mathrm{L}$. The plots of dye removal (\%) vs. time at different initial BB41 concentrations are shown in Fig. 7. The removal dye (\%) shows a decreasing trend as the initial dye concentration of the dye is increased. At lower concentrations, all adsorbate ions present in the medium could interact with the binding sites, resulting in higher dye removal (\%). At higher concentrations, the dye removal (\%) shows a decreasing behavior because of the saturation of the adsorption sites. Similarly, the adsorption equilibrium was achieved after $120 \mathrm{~min}$ of stirring the appropriate dye solution with the C-PAN adsorbent. At this time, the removal of BB41 (\%) decreased from 99 to $77.5 \%$ for the initial BB41 concentration of 25 to $125 \mathrm{mg} / \mathrm{L}$. However, the amount of BB41 adsorbed onto C-PAN, $q_{\mathrm{e}}(-$ $\mathrm{mg} / \mathrm{g}$ ) was found to increase from 124.41 to $484.35 \mathrm{mg} / \mathrm{g}$ upon increasing the initial dye concentration

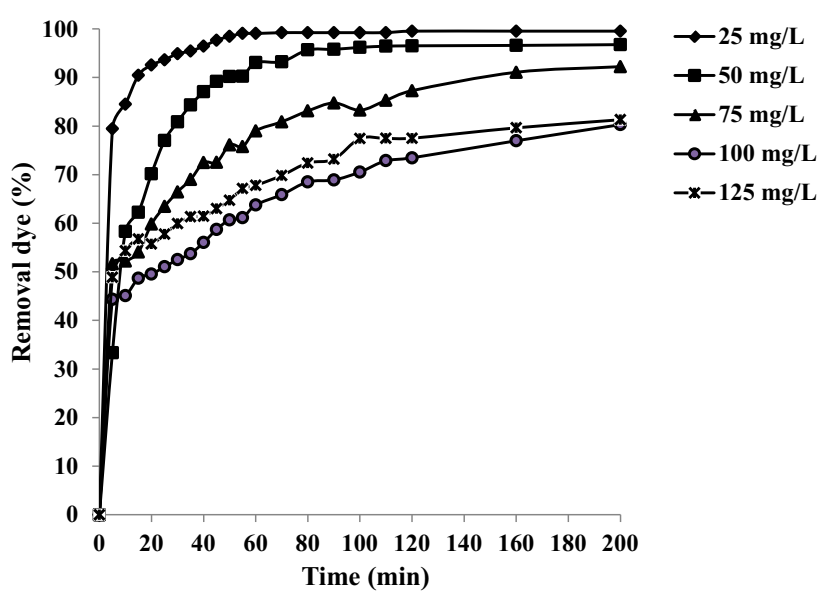

Fig. 7 Effect of initial dye concentration and contact time on the removal of BB41 from aqueous solution. C-PAN $30 \mathrm{mg} / \mathrm{L}$; temperature $20{ }^{\circ} \mathrm{C}$ 


\section{Adsorption kinetics}

To study the sorption process of BB41 onto C-PAN adsorbent, the data obtained from kinetic adsorption experiments were simulated with pseudo-first-order and pseudo-second-order models.

The pseudo-first-order equation is generally represented as follows [40]:

$\log \left(q_{\mathrm{e}}-q_{t}\right)=\log \left(q_{\mathrm{e}}\right)-\frac{k_{1}}{2.303} t$,

where $q_{\mathrm{e}}$ is the amount of dye adsorbed at equilibrium (mg/ $\mathrm{g}), q_{t}$ the amount of dye adsorbed at time $t(\mathrm{mg} / \mathrm{g}), k_{1}$ the pseudo-first-order rate constant $\left(\min ^{-1}\right)$ and $t$ the time (min).

The values of $k_{1}, q_{\mathrm{e}}$ calculated from the equation and the correlation coefficient $\left(R^{2}\right)$ values of fitting the first-order rate model at different concentrations are presented in Table 1 . The linearity plots of $\log \left(q_{\mathrm{e}}-q_{t}\right)$ versus time at different initial dye concentrations (Fig. 8) suggested that the process of dye adsorption did not follow the pseudofirst-order rate kinetics. Also from Table 1, it is indicated that the values of the correlation coefficients are not high for the different dye concentrations. Furthermore, the estimated values of $q_{\mathrm{e}}$ calculated from the equation qe differ substantially from those measured experimentally. This gives confirmation that the adsorption process of BB41 onto C-PAN did not obey the pseudo-first-order model.

The pseudo-second-order equation is generally represented as follows [41]:

$\frac{t}{q_{\mathrm{t}}}=\frac{1}{k_{2} q_{\mathrm{e}}^{2}}+\frac{1}{q_{\mathrm{e}}} t$,

where $k_{2}$ is the pseudo-second-order rate constant ( $\mathrm{g} /$ $\mathrm{mg}$ min).

A plot of $t / q_{t}$ and $t$ should give a linear relationship if the adsorption follows pseudo-second-order model. To understand the applicability of the model, a linear plot of $t / q_{t} \mathrm{vs}$. $t$ under different dye concentrations was plotted as in Fig. 9. The constants $k_{2}, q_{\mathrm{e}}$ and correlation coefficients $\left(R^{2}\right)$

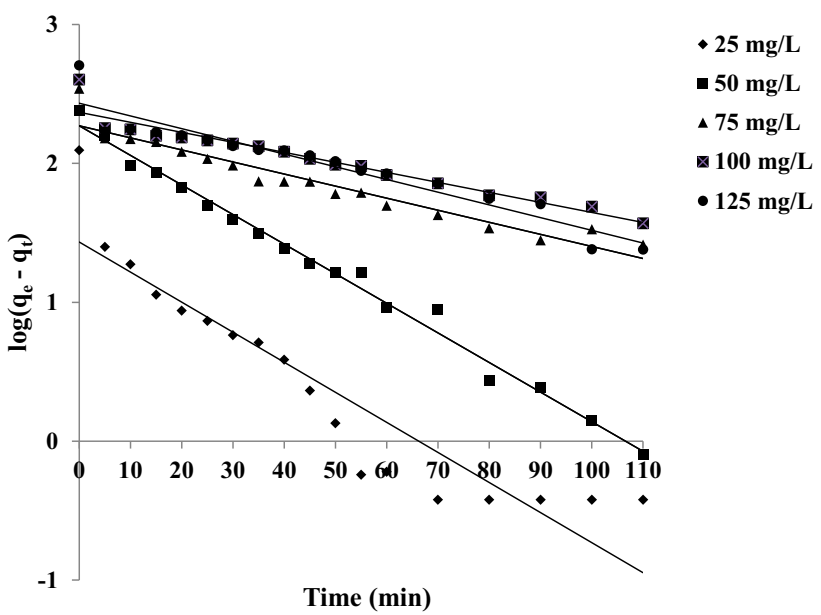

Fig. 8 Pseudo-first-order plots for different initial dye concentrations removal using C-PAN adsorbent. C-PAN adsorbent $30 \mathrm{mg}$; temperature $20{ }^{\circ} \mathrm{C}$

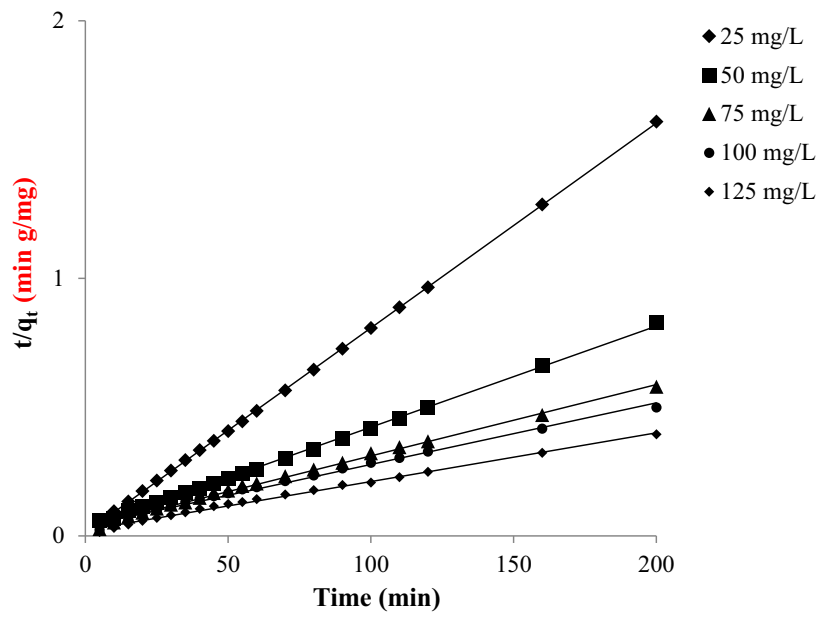

Fig. 9 Pseudo-second-order plots for different initial dye concentration removal using C-PAN adsorbent. C-PAN adsorbent $30 \mathrm{mg}$; temperature $20{ }^{\circ} \mathrm{C}$

were calculated from the plot and are given in Table 1 . The $q_{\mathrm{e}}$ determined from the model along with correlation coefficients indicated that $q_{\mathrm{e}}$ was very close to $q_{\exp }$ and the

Table 1 The pseudo-first-order and pseudo-second-order kinetic parameters for BB41 removal using C-PAN

\begin{tabular}{|c|c|c|c|c|c|c|c|}
\hline \multirow[t]{2}{*}{ Concentration of BB41 (mg/L) } & \multicolumn{4}{|c|}{ Pseudo-first order } & \multicolumn{3}{|l|}{ Pseudo-second order } \\
\hline & $q_{\mathrm{e}}, \exp (\mathrm{mg} / \mathrm{g})$ & $k_{1}\left(\min ^{-1}\right)$ & $q_{\mathrm{e}}, \mathrm{cal}(\mathrm{mg} / \mathrm{g})$ & $r^{2}$ & $k_{2} \times 10^{-4}(\mathrm{~g} / \mathrm{mg} \min )$ & $q_{\mathrm{e}}, \mathrm{cal}(\mathrm{mg} / \mathrm{g})$ & $r^{2}$ \\
\hline 25 & 124.41 & 0.0493 & 027.03 & 0.862 & 59.65 & 123.45 & 0.999 \\
\hline 50 & 241.90 & 0.0483 & 186.63 & 0.989 & 5.248 & 256.41 & 0.999 \\
\hline 75 & 345.84 & 0.0184 & 234.96 & 0.918 & 2.548 & 344.82 & 0.997 \\
\hline 100 & 401.45 & 0.0161 & 233.34 & 0.928 & 1.689 & 400.00 & 0.992 \\
\hline 125 & 508.13 & 0.0207 & 271.01 & 0.906 & 1.616 & 502.51 & 0.995 \\
\hline
\end{tabular}


correlation coefficient was also greater than 0.99. As a matter of consequence, the system BB41-C-PAN could be well described by the pseudo-second-order model. This adequate model shows that the adsorption of BB41 onto C-PAN is controlled by chemisorption mechanism.

\section{Adsorption isotherms}

Adsorption isotherms are basic requirements for the design of adsorption systems. It can express the relationship between the amounts of adsorbate by unit mass of adsorbent at a constant temperature. Herein, we analyzed our experimental data by Langmuir and Freundlich isotherms models. The best-fitting model was evaluated using the correlation coefficient.

The Langmuir model [42] permits the evaluation of maximum dye adsorption capacity when all sites have equal affinities and active sites of adsorbent are independent of each other. The linear form of the Langmuir isotherm is expressed as follows:

$\frac{C_{\mathrm{e}}}{q_{\mathrm{e}}}=\frac{1}{q_{\mathrm{m}} K_{\mathrm{L}}}+\frac{1}{q_{\mathrm{m}}} C_{\mathrm{e}}$,

where $C_{\mathrm{e}}(\mathrm{mg} / \mathrm{L})$ is the equilibrium concentration of the BB41 dye and $q_{\mathrm{e}}(\mathrm{mg} / \mathrm{g})$ is the amount of BB41 adsorbed per unit mass of adsorbent. $q_{\mathrm{m}}(\mathrm{mg} / \mathrm{g})$ and $K_{\mathrm{L}}(\mathrm{L} / \mathrm{mg})$ are the constants related to the maximum adsorption capacity and is the Langmuir constant, respectively.

A straight line with a slope of $1 / q_{\mathrm{m}}$ and intercept of $1 / q_{\mathrm{m}}$ $K_{\mathrm{L}}$ is obtained when $C_{\mathrm{e}} / q_{\mathrm{e}}$ is plotted against $C_{\mathrm{e}}$. Table 2 shows the values of these parameters.

The essential characteristics of the Langmuir equation can be expressed in terms of the dimensionless separation factor, $R_{\mathrm{L}}$, defined as:

$R_{\mathrm{L}}=\frac{1}{1+K_{\mathrm{L}} C_{0}}$,

Table 2 Adsorption isotherm constants for removal of BB41 onto the C-PAN adsorbent

\begin{tabular}{lccr}
\hline \multicolumn{4}{c}{ Temperature } \\
\cline { 2 - 4 } & $298 \mathrm{~K}$ & $303 \mathrm{~K}$ & $313 \mathrm{~K}$ \\
\hline Langmuir isotherm & & & \\
$q_{\mathrm{m}}(\mathrm{mg} / \mathrm{g})$ & 500.00 & 555.55 & 625.00 \\
$K_{\mathrm{L}}(\mathrm{L} / \mathrm{mg})$ & 0.66 & 0.75 & 0.80 \\
$r^{2}$ & 0.997 & 0.995 & 0.991 \\
Freundlich isotherm & & & \\
$K_{\mathrm{F}}(\mathrm{mg} / \mathrm{g})(\mathrm{L} / \mathrm{g})$ & 213.80 & 269.15 & 359.74 \\
$n$ & 4.03 & 3.97 & 4.10 \\
$r^{2}$ & 0.982 & 0.984 & 0.979 \\
\hline
\end{tabular}

where $C_{0}$ is the initial concentration of the BB41 dye; the $R_{\mathrm{L}}$ value implies whether the adsorption is unfavorable: $R_{\mathrm{L}}>1$, linear: $R_{\mathrm{L}}=1$, favorable: $0<R_{\mathrm{L}}<1$, or irreversible: $R_{\mathrm{L}}=0$.

Figure 10 depicts the plot of the calculated $R_{\mathrm{L}}$ values versus the initial dye concentration at 298, 303 and $313 \mathrm{~K}$. It was observed that all the $R_{\mathrm{L}}$ values obtained were between 0 and 1 , showing that the adsorption of BB41 onto C-PAN was favorable. The $R_{\mathrm{L}}$ values decrease upon increasing the initial dye concentration, which indicates that the adsorption is more favorable at higher BB41 concentrations. The adsorption capacity increases on increasing the temperature, attaining a higher value of adsorption capacity of $625 \mathrm{mg} / \mathrm{g}$ at $313 \mathrm{~K}$. The values of $K_{\mathrm{L}}$ increased on an increase in temperature. Therefore, by increasing the temperature, higher adsorption capacities were achieved.

Freundlich isotherm [43] is observed if the sites with stronger binding affinities are occupied by the dye molecules first and the binding strength decreases with increase in the degree of site occupation. The linear form of the Freundlich isotherm is expressed as follows:

$\log \left(q_{\mathrm{e}}\right)=\log \left(K_{\mathrm{f}}\right)+\frac{1}{n} \log \left(C_{\mathrm{e}}\right)$,

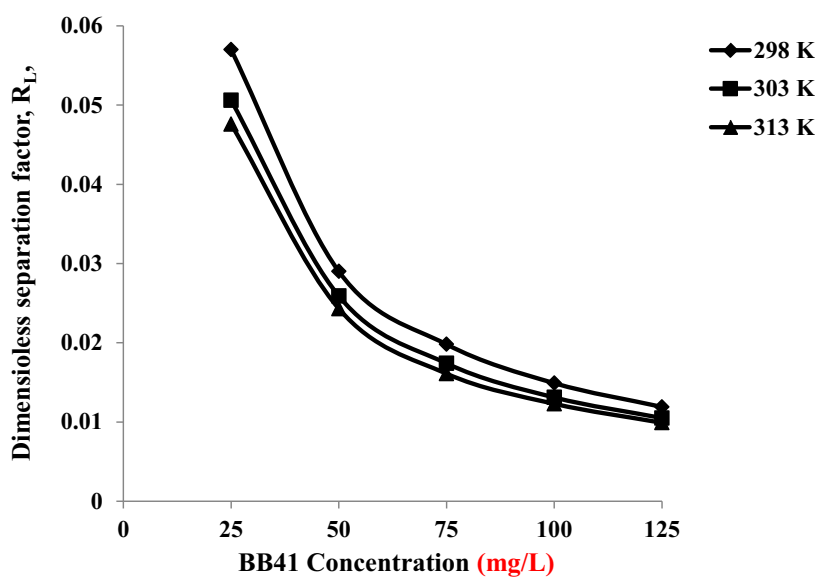

Fig. 10 Dimensionless separation factor, $R_{\mathrm{L}}$, versus concentration dye

Table 3 Thermodynamic data for the adsorption of BB41 onto C-PAN

\begin{tabular}{lrlll}
\hline$T(\mathrm{~K})$ & \multicolumn{1}{c}{$K_{\mathrm{C}}$} & $\Delta G^{0}(\mathrm{~kJ} / \mathrm{mol})$ & $\Delta H^{0}(\mathrm{~kJ} / \mathrm{mol})$ & $\Delta S^{0}(\mathrm{~J} / \mathrm{mol} \mathrm{K})$ \\
\hline 298 & 106.51 & -11.64 & 144.6 & 524.3 \\
303 & 287.90 & -14.26 & & \\
313 & 624.08 & -16.88 & & \\
323 & 1354.26 & -19.50 & & \\
\hline
\end{tabular}


Table 4 Comparison of the maximum monolayer adsorption capacities of C-PAN with those of various $\mathrm{AC}$ adsorbents

\begin{tabular}{lllll}
\hline AC adsorbent & Dye & Isotherm & $q_{\mathrm{m}}(\mathrm{mg} / \mathrm{g})$ & Reference \\
\hline Pomegranate peel & Remazol brilliant & Freundlich & 370.86 & {$[44]$} \\
Homemade cocoa shell & Reactive violet 5 & Liu & 603.3 & {$[45]$} \\
Rambutan peel & Acid yellow 17 & Langmuir & 215.05 & {$[46]$} \\
Rice husks & Methylene blue & Langmuir & 578 & {$[47]$} \\
Pomelo skin & Methylene blue & Langmuir & 501.1 & {$[48]$} \\
Stricta algae based & Safranin O & Langmuir & 526 & {$[49]$} \\
Persea americana & Basic Blue 41 & Langmuir & 625 & This study \\
\hline
\end{tabular}

\section{Comparison of adsorption capacities of C-PAN with those of various $\mathrm{AC}$ adsorbents}

where $K_{\mathrm{f}}(\mathrm{mg} / \mathrm{g})(\mathrm{L} / \mathrm{g})$ and $n$ are Freundlich constants respectively.

The Freundlich constants $n$ and $K_{\mathrm{f}}$ were obtained from the plot of $\log \left(q_{\mathrm{e}}\right)$ versus $\log \left(C_{\mathrm{e}}\right)$ that should give a straight line with a slope of $(1 / n)$ and intercept of $\log \left(K_{\mathrm{f}}\right)$ (as shown in Table 2). In this study, the values found for $n$ were superior to 1 , which indicates that the adsorption of BB41 onto C-PAN is favorable.

\section{Thermodynamic study}

The thermodynamic data reflect the feasibility and favorability of the adsorption. The parameters such as free energy change $\left(\Delta G^{0}\right)$, enthalpy change $\left(\Delta H^{0}\right)$ and entropy change $\left(\Delta S^{0}\right)$ can be estimated by the change of equilibrium constants with temperature. The free energy change of the sorption reaction is given by:

$\Delta G^{0}=-R T \ln K_{C}$,

where $\Delta G^{0}$ is the free energy change $(\mathrm{kJ} / \mathrm{mol}), R$ the universal gas constant $(8.314 \mathrm{~J} / \mathrm{mol} \mathrm{K}), T$ the absolute temperature $(K)$ and $K_{\mathrm{C}}$ the equilibrium constants $\left(q_{\mathrm{e}} / C_{\mathrm{e}}\right)$. The values of $\Delta H^{0}$ and $\Delta S^{0}$ can be calculated from the Van't Hoff equation:

$\ln K_{C}=-\frac{\Delta H^{0}}{R T}+\frac{\Delta S^{0}}{R}$,

where $\mathrm{LnK}_{\mathrm{C}}$ is plotted against $1 / T$, and a straight line with the slope $\left(-\Delta H^{0} / R\right)$ and intercept $\left(\Delta S^{0} / R\right)$ are found. The calculated thermodynamic parameters are depicted in Table 3.

In the study, $\Delta G^{0}$ values were determined at different temperatures and decrease from -11.64 to $-19.50 \mathrm{~kJ} / \mathrm{mol}$ when the temperature increases from 298 to $323 \mathrm{~K}$. The negative values of $\Delta G^{0}$ suggest that the adsorption of BB41 onto C-PAN is a highly favorable process. The values of $\Delta H^{0}$ and $\Delta S^{0}$ were obtained as 144.6 and $524.3 \mathrm{~J} / \mathrm{mol} \mathrm{K}$, respectively. The positive value of $\Delta H^{0}$ shows that the adsorption is an endothermic process, while a positive value of $\Delta S^{0}$ reflects the increase of randomness state at the solid/solution interface during the adsorption.
Table 4 depicts the values of maximum monolayer adsorption capacities of many AC adsorbents. It appeared that C-PAN can be classed belong the best ACs adsorbents with an adsorption capacity of $625 \mathrm{mg} / \mathrm{g}$.

\section{Conclusion}

Based on the results obtained in this study, it appears that the activated carbon prepared from Persea American nut constitutes a good adsorbent for removing a dye from aqueous solutions:

- The percent (\%) removal of BB41 was observed to increase with increasing initial dye concentration and increasing adsorbent dose.

- The Langmuir isotherm best described the equilibrium data with acceptable $R^{2}$, which signifies that a homogeneous adsorption takes place between the BB41 dye and C-PAN.

- The pseudo-second-order equation best describes the kinetics of the C-PAN adsorption system due to its high $R^{2}$. In addition, the theoretical $q_{\mathrm{e}}$ generated by the pseudo-second-order equation is in good agreement with the experimental $\mathrm{q}_{\mathrm{e}}$ value. This implies that the rate-limiting step is a chemisorption process.

- Thermodynamic studies indicated that the adsorption process is endothermic and spontaneous.

Open Access This article is distributed under the terms of the Creative Commons Attribution 4.0 International License (http://crea tivecommons.org/licenses/by/4.0/), which permits unrestricted use, distribution, and reproduction in any medium, provided you give appropriate credit to the original author(s) and the source, provide a link to the Creative Commons license, and indicate if changes were made.

\section{References}

1. Yagub MT, Sen TK, Afroze S, Ang HM (2014) Dye and its removal from aqueous solution by adsorption: a review. Adv Colloid Interface Sci 209:172-184 
2. Banat IM, Nigam P, Singh D, Marchant R (1996) Microbial decolorization of textile-dye containing effluents: a review. Bioresour Technol 58:217-227

3. Rafatullah M, Sulaiman O, Hashim R, Ahmad A (2010) Adsorption of methylene blue on low-cost adsorbents: a review. J Hazard Mater 177:70-80

4. Vakili M, Rafatullah M, Salamatinia B, Abdullah AZ, Ibrahim MH, Tan KB, Gholami Z, Amouzgar P (2014) Application of chitosan and its derivatives as adsorbents for dye removal from water and wastewater: a review. Carbohyd Polym 113:115-130

5. Gupta VK, Jain R, Nayak A, Agarwal S, Shrivastava M (2011) Removal of the hazardous dye-Tartrazine by photodegradation on titanium dioxide surface. J Hazard Mater 31:1062-1067

6. Ahmad T, Danish M, Rafatullah M, Ghazali A, Sulaiman O, Hashim R, Ibrahim MN (2012) The use of date palm as a potential adsorbent for wastewater treatment: a review. Environ Sci Technol 19:1464-1484

7. Low LW, Teng T, Rafatullah M, Morad N, Azahari B (2014) adsorption studies of methylene blue and malachite green from aqueous solutions by pretreated lignocellulosic materials. Separ Sci Technol 48:1688-1698

8. Mittal A, Mittal J, Malviya A, Kaur D, Gupta VK (2010) Decoloration treatment of a hazardous triarylmethane dye, light green SF (Yellowish) by waste material adsorbents. J Colloid Interface Sci 342:518-527

9. Gupta VK, Nayak A (2012) Cadmium removal and recovery from aqueous solutions by novel adsorbents prepared from orange peel and $\mathrm{Fe}_{2} \mathrm{O}_{3}$ nanoparticles. Chem Eng J 180:81-90

10. Gupta VK, Jain R, Mittal A, Tawfik A, Saleh A, Naya A, Agarwal S, Sikarwa S (2012) Photo-catalytic degradation of toxic dye amaranth on $\mathrm{TiO}_{2} / \mathrm{UV}$ in aqueous suspensions. Mater Sci Eng C 32:12-17

11. Saleh TA, Gupta VK (2012) Photo-catalyzed degradation of hazardous dye methyl orange by use of a composite catalyst consisting of multi-walled carbon nanotubes and titanium dioxide. J Colloid Interface Sci 371:101-106

12. Gupta VK, Ali I, Saleh TA, Nayak A, Agarwal S (2012) Chemical treatment technologies for waste-water recycling-an overview. RSC Adv 2:6380-6388

13. Gupta VK, Srivastava SK, Mohan D, Sharma S (1997) Design parameters for fixed bed reactors of activated carbon developed from fertilizer waste for the removal of some heavy metal ions. Waste Manage 17:517-522

14. Mittal A, Kaur A, Malviya A, Mittal J, Gupta VK (2009) Adsorption studies on the removal of coloring agent phenol red from wastewater using waste materials as adsorbents. J Colloid Interface Sci 337:345-354

15. Mittal A, Mittal J, Malviya A, Gupta VK (2009) Adsorptive removal of hazardous anionic dye "Congo red" from wastewater using waste materials and recovery by desorption. J Colloid Interface Sci 340:16-26

16. Gupta VK, Kumar R, Nayak A, Saleh TA, Barakat MA (2013) Adsorptive removal of dyes from aqueous solution onto carbon nanotubes: a review. Adv Colloid Interface Sci 193-194:24-34

17. Gupta VK, Nayak A, Bhushan B, Agarwal S (2015) A critical analysis on the efficiency of activated carbons from low-cost precursors for heavy metals remediation. Crit Rev Environ Sci Technol 45:613-668

18. Mittal A, Mittal J, Malviya A, Gupta VK (2010) Removal and recovery of Chrysoidine $\mathrm{Y}$ from aqueous solutions by waste materials. J Colloid Interface Sci 344:497-507

19. Ncibi MC, Sillanpää M (2015) Mesoporous carbonaceous materials for single and simultaneous removal of organic pollutants: activated carbons vs. carbon nanotubes. J Mol Liq 207:237-247
20. Ahmad AA, Hameed BH, Ahmad AL (2009) Removal of disperse dye from aqueous solution using waste-derived activated carbon: optimization study. J Hazard Mater 170:612-619

21. Yu L, Luo Y (2014) The adsorption mechanism of anionic and cationic dyes by Jerusalem artichoke. J Environ Chem Eng 2:220-229

22. Luna MD, Flores ED, Genuino DA, Futalan CM, Wan MW (2013) Adsorption of Eriochrome Black T (EBT) dye using activated carbon prepared from waste rice hulls-optimization, isotherm and kinetic studies. J Taiwan Ins Chem Eng 44:646-653

23. Ribas MC, Adebayo MA, Prola LD, Lima EC, Cataluña R, Feris LA, Puchana-Rosero MJ, Machado FM, Pavan FA, Calvete T (2014) Comparison of a homemade cocoa shell activated carbon with commercial activated carbon for the removal of reactive violet 5 dye from aqueous solutions. Chem Eng J 248:315-326

24. Auta M, Hameed BH (2011) Optimized waste tea activated carbon for adsorption of Methylene Blue and Acid Blue 29 dyes using response surface methodology. Chem Eng J 175:233-243

25. Santhy K, Selvapathy P (2006) Removal of reactive dyes from wastewater by adsorption on coir pith activated carbon. Bioresour Technol 97:1329-1336

26. Fernandez ME, Nunell GV, Bonelli PR, Cukierman AL (2014) Activated carbon developed from orange peels: batch and dynamic competitive adsorption of basic dyes. Ind Crops Products 62:437-445

27. Asadullah M, Asaduzzaman M, Kabir MS, Mostofa MG, Miyazawa T (2010) Chemical and structural evaluation of activated carbon prepared from jute sticks for Brilliant Green dye removal from aqueous solution. J Hazard Mater 174:437-443

28. Heibati B, Rodriguez-Couto S, Amrane A, Rafatullah M, Hawari A, Al-Ghouti MA (2014) Uptake of Reactive Black 5 by pumice and walnut activated carbon: chemistry and adsorption mechanisms. J Ind Eng Chem 20(5):2939-2947

29. Rafatullah M, Ahmad T, Ghazali A, Sulaiman O, Danish M, Hashim R (2013) Oil palm biomass as a precursor of activated carbons: a review. Crit Rev Environ Sci Technol 43:1117-1161

30. Danish M, Hashim R, Mohamad Ibrahim MN, Rafatullah M, Ahmad T, Sulaiman O (2011) Characterization of acacia mangium wood based activated carbons prepared in the presence of basic activating agents. Bioresour Technol 6(3):3019-3033

31. Saleh TA, Gupta VK (2014) Processing methods: characteristics and adsorption behavior of tire derived carbons: a review. Adv Colloid Interf Sci 211:92-100

32. Liang S, Guo X, Tian Q (2011) Adsorption of $\mathrm{Pb}^{2+}$ and $\mathrm{Zn}^{2+}$ from aqueous solutions by sulfured orange peel. Desalination 275:212-216

33. He J, Ma Y, He J, Zhao J, Yu JC (2002) Photooxidation of azo dye in aqueous dispersions of $\mathrm{H} 2 \mathrm{O} 2 / \alpha-\mathrm{FeOOH}$. Appl Catal B Environ 39:211-220

34. Pavia DL, Lampman, GM, Kaiz GS (1987) Introduction to spectroscopy: a guide for students of organic chemistry. W B Saunders Company

35. Liu H, Zhang J, Bao N, Cheng C, Ren L, Zhang C (2012) Textural properties and surface chemistry of lotus stalk-derived activated carbons prepared using different phosphorus oxyacids: adsorption of trimethoprim. J Hazard Mater 235:236367-236375

36. Wang Z, Nie E, Li J, Zhao Y, Luo X, Zheng Z (2011) Carbons prepared from Spartina alterniflora and its anaerobically digested residue by $\mathrm{H} 3 \mathrm{PO} 4$ activation: characterization and adsorption of cadmium from aqueous solutions. J Hazard Mater 188:29-36

37. Syed Shabudeen PS, Venckatsh R, Pattabhi S (2006) Preparation and utilization of kapok hull carbon for the removal of rhodamine B from aqueous solution. J Chem 3:83-96

38. Mohan D, Singth KP, Sinha S, Gosh D (2001) Removal of pyridine from aqueous solution using low cost activated carbons derived from agricultural waste materials. Carbon 42:2409-2421 
39. Hu Z, Chen H, Ji K, Yuan S (2010) Removal of Congo red from aqueous solution by cattail root. J Hazard Mater 173:292-297

40. Ozcan A, Omeroglu C, Erdogan Y, Ozcan AS (2007) Modification of bentonite with a cationic surfactant: an adsorption study of textile dye Reactive Blue 19. J Hazard Mater 140:173-179

41. Moussavi G, Mahmoudi M (2009) Removal of azo and anthraquinone reactive dyes from industrial wastewaters using $\mathrm{MgO}$ nanoparticles. J Hazard Mater 168:806-812

42. Langmuir I (1916) The constitution and fundamental properties of solids and liquids. J Am Chem Soc 39:2221-2295

43. Freundlich MF (1906) Over the adsorption in solution. J Phys Chem 57:385-470

44. Mohd AA, Nur AA, Olugbenga SB (2014) Kinetic, equilibrium and thermodynamic studies of synthetic dye removal using pomegranate peel activated carbon prepared by microwave-induced $\mathrm{KOH}$ activation. Water Resour Ind 6:18-35

45. Marielen CR, Matthew AA, Lizie TP, Eder CL, Renato C, Liliana AF, Puchana-Rosero MJ, Fernando MM, Flávio P, Calvete T
(2014) Comparison of a homemade cocoa shell activated carbon with commercial activated carbon for the removal of reactive violet 5 dye from aqueous solutions. Chem Eng J 248:315-326

46. Njoku VO, Foo KY, Asif M, Hameed BH (2014) Preparation of activated carbons from rambutan(Nephelium lappaceum) peel by microwave-induced $\mathrm{KOH}$ activation for acid yellow 17 dye adsorption. Chem Eng J 250:198-204

47. Chen Y, Zhai SR, Liu N, Song Y, An QD, Song XW (2013) Dye removal of activated carbons prepared from $\mathrm{NaOH}$-pretreated rice husks by low-temperature solution-processed carbonization and $\mathrm{H}_{3} \mathrm{PO}_{4}$ activation. Bioresour Technol 144:401-409

48. Foo KY, Hameed BH (2011) Microwave assisted preparation of activated carbon from pomelo skin for the removal of anionic and cationic dyes. Chem Eng J 173:385-390

49. Attouti S, Bestani B, Benderdouche N, Laurent D (2013) Application of Ulva lactuca and Systoceira stricta algae-based activated carbons to hazardous cationic dyes removal from industrial effluents. Water Res 47:3375-3388 